\title{
Association between miR-196a2 polymorphism and the development of hepatocellular carcinoma in the Egyptian population
}

\author{
Eman Ahmed Gawish, Gamal Yousef Abu-Raia, Iman Osheba, Aliaa Sabry and Esraa Allam
}

\begin{abstract}
Background: Hepatocellular carcinoma (HCC) is one of the most prevalent cancers worldwide. Circulating microRNAs (miRNAs) are endogenous, small (17-25 nucleotides) non-coding RNAs that are overexpressed in many human cancers including HCC. Single-nucleotide polymorphisms (SNPs) of miRNAs play an important role in the pathogenesis of HCC. In our study, we aimed to evaluate the role of miR-196a2 rs11614913 polymorphism in the development of HCC. A total of 200 subjects, including 80 HCC patients, 60 patients with liver cirrhosis, and 60 healthy controls were selected. The polymerase chain reaction-restriction fragment length polymorphism (PCRRFLP) was taken to determine miR-196a2 rs11614913 polymorphism.
\end{abstract}

Results: The genotype distribution of the $T C$ and $C C, T C+C C$ genotypes, and the $C$ allele were significantly higher in HCC patients than control and cirrhotic groups $(P=0.02, P=0.005$, and $P=0.003$, respectively). Compared with the wild-type $\Pi$ genotype, both the variant TC, CC, TC + CC genotypes were associated with an elevated risk of $\mathrm{HCC}(\mathrm{OR}=2.77,95 \% \mathrm{Cl}=1.27-6.04),(\mathrm{OR}=4.94,95 \% \mathrm{Cl}=1.74-14.07),(\mathrm{OR}=3.24,95 \% \mathrm{Cl}=1.55-6.78)$ respectively. Moreover, the $\mathrm{C}$ allele was correlated with an increased risk of HCC $(\mathrm{OR}=2.30,95 \% \mathrm{Cl}=1.40-3.76)$ compared to the wide-type T allele. Also, there is no significant correlation between the different miR-196a2 genotypes and either the clinico-pathologic features of HCC or its aggressiveness.

Conclusion: Our results suggest that the miR-196a2 rs11614913 polymorphism is associated with an increased risk of HCC in the Egyptian population.

Keywords: Hepatocellular carcinoma, MiR-196a2, Polymorphism

\section{Background}

HCC represents a global health problem. It is one of the most common malignant tumors and the third cause of cancer-related mortality per year with high incidence worldwide [1].

The etiology of HCC is complex; there are many risk factors such as infection with hepatitis $\mathrm{B}$ or $\mathrm{C}$ virus (HBV, HCV), alcohol abuse, nonalcoholic steatohepatitis (NASH) and aflatoxin exposure. HCC usually develops in patients with liver cirrhosis due to chronic inflammation and advanced fibrosis [2].

\footnotetext{
* Correspondence: esraaallam1980@gmail.com

Department of Laboratory Medicine, National Liver Institute, Menoufia University, Menoufia, Egypt
}

MicroRNAs (miRNAs) are a class of small non-coding RNAs, approximately $\sim 22$ nucleotides long, that perform important roles in the regulation of mammalian gene expression via post-transcriptional repression by directly binding to the 3' untranslated region (UTR) of messenger RNAs (mRNAs), resulting in downregulation of their expression [3].

MiRNAs have been showed to play important roles in regulating different biological processes, including cell differentiation, proliferation, and apoptosis. SNPs of miRNAs may influence their functions through altering miRNA expression, maturation, and/or efficiency of targeting and, thereby, contribute to the risk of cancer [4]. 
The miR-196a-2 gene is located in a region between homeobox (HOX) clusters $\mathrm{HOXC10}$ and HOXC9 on chromosome 12 . The miR-196a-2 is thought to be overexpressed in HCC tissues and plays important roles in the pathogenesis and development of HCC [5].

Several studies demonstrated the association of miR196a-2 gene with many cancers including colon, prostate, pancreatic, lung, breast, urinary bladder, and kidney cancer [6].

The present study was designed to evaluate the role of miR-196a2 rs11614913 polymorphism in the development of $\mathrm{HCC}$ in the Egyptian population.

\section{Methods}

The present study was conducted at the clinical pathology department, National Liver Institute, Menoufia University, in the duration between September 2017 and December 2018. A total of 200 subjects were enrolled in this case-control study, including 80 patients with $\mathrm{HCC}$, 60 patients with cirrhosis with no radiological evidence of HCC and 60 apparently healthy individuals matched in age and sex as a control group, with no previous history of liver or malignant diseases and negative for hepatitis viral markers. Patients with HCC (diagnosed according to definitive criteria in triphasic computed tomography (CT) with contrast showing arterial enhancement and delayed venous washout) were excluded if they have inflammatory diseases, hematological malignancy, and cancer of any organ other than the liver. The study protocol was approved by the local ethics committee of the National Liver Institute, Menoufia University. Informed consent was taken from both the patients and control group subjects after explaining the aim and concerns of the study.

For all subjects, the followings were done: collection of relevant clinical data, basic laboratory tests including liver function tests (Cobas-6000 auto analyzer, Roche Diagnostics, Germany), Alpha-fetoprotein (AFP) (Cobas e411 immunoassay analyzer, Roche Diagnostics, Germany), prothrombin time (Coagulometer CA - 1500, Siemens, Germany). Hepatitis serology (HBsAg and $\mathrm{HCV} \mathrm{Ab}$ ) (Cobas e411 immunoassay analyzer, Roche Diagnostics, Germany). Molecular testing for miR-196a2 rs11614913 polymorphism was done by PCR-RFLP assay.

\section{DNA extraction and genotyping}

Total DNA was extracted from EDTA treated blood samples using Zymo Quick-gDNA ${ }^{\mathrm{Tm}}$ MiniPrep DNA Purification Kit (Zymo Research, CA, USA).

After ethanol precipitation, the DNA was purified and dissolved in double distilled water and frozen at $-20{ }^{\circ} \mathrm{C}$ until use. The miR-196a2 genotype was determined by polymerase chain reaction-restriction fragment length polymorphism assay (PCR-RFLP). The PCR primers
(Thermo scientific) were as follows: forward $5^{\prime}$ CCCCTTCCCTTCTCCTCCAGATA-3' and reverse 5' CGAAAACCGACTGATGTAACTCCG-3'. PCR cycling conditions were $5 \mathrm{~min}$ at $94^{\circ} \mathrm{C}$, followed by 30 cycles of $30 \mathrm{~s}$ at $94{ }^{\circ} \mathrm{C}, 30 \mathrm{~s}$ at $63^{\circ} \mathrm{C}$, and $60 \mathrm{~s}$ at $72{ }^{\circ} \mathrm{C}$, with a final elongation step at $72{ }^{\circ} \mathrm{C}$ for $10 \mathrm{~min}$. For restriction fragment length polymorphism, the PCR products were digested with 5 units MsPI enzyme (New England Biolabs, USA) at $37^{\circ} \mathrm{C}$ and visualized by electrophoresis on $2 \%$ agarose under ultraviolet (UV) illumination. The allele types were determined as follows: a single $149 \mathrm{bp}$ fragment for the TT genotype, 2 fragments of 24 and 125 bp for the CC genotype, and 3 fragments of 24, 125, and $149 \mathrm{bp}$ for the TC genotype.

\section{Statistical analysis}

Statistical analysis of the present study was conducted using SPSS version 17.0 (SPSS Inc., Chicago, IL, USA). Data was expressed into two phases: descriptive and analytical study chi-square test, one-way ANOVA test, Kruskal-Wallis test, Fisher's exact test, odds ratio (OR), and confidence interval $(\mathrm{CI})$ test were used. $P$ value $>0.05$ was considered statistically non-significant. $P$ value $<0.05$ was considered statistically significant. $P$ value $0.000(<0.001)$ was considered statistically highly significant.

\section{Results}

\section{Baseline characteristics of the study subjects}

There is no significant difference between the three statistically studied groups as regard age $(P=0.06)$ and gender $(P=0.88)$. However, there is a statistically highly significant difference between the three groups regarding smoking $(P=<0.001)$ and family history of HCC $(P=<0.001)$ (Table 1). Also, there was a statistically significant difference between studied groups as regarding alanine aminotransferase (ALT), aspartate aminotransferase (AST), total and direct bilirubin, serum albumin, and international normalized ratio (INR) (Table 2).

\section{MiR-196a2 genotypes and alleles distribution among study subjects}

The frequency distributions of the different genotypes for miR-196a2 polymorphism are shown in (Fig. 1 and Table 3). There was a statistically significant difference between HCC patients and each of the other groups. HCC patients had a higher incidence of CC and TC genotypes when compared to cirrhotic patients and healthy controls; $P=0.02,0.005$, respectively. Allele frequencies showed a statistically higher incidence of $\mathrm{C}$ allele in HCC patients compared to cirrhotic patients and healthy controls; $P=0.003$. 
Table 1 Socio-demographic data of the studied groups

\begin{tabular}{|c|c|c|c|c|c|c|c|c|}
\hline & \multicolumn{2}{|c|}{$\begin{array}{l}\text { Control } \\
N=60\end{array}$} & \multicolumn{2}{|c|}{$\begin{array}{l}\text { Cirrhosis } \\
N=60\end{array}$} & \multicolumn{2}{|c|}{$\begin{array}{l}\mathrm{HCC} \\
N=80\end{array}$} & $x^{2}$ & $P$ value \\
\hline \multicolumn{9}{|l|}{ Age (years) } \\
\hline$X \pm S D$ & \multicolumn{2}{|c|}{$52.61 \pm 7.5$} & \multicolumn{2}{|c|}{$56.92 \pm 6.45$} & \multicolumn{2}{|c|}{$54.04 \pm 8.34$} & \multirow{3}{*}{${ }^{*} F=2.89$} & \multirow{3}{*}{0.06} \\
\hline \multirow[t]{2}{*}{ Min-max } & \multicolumn{2}{|c|}{$24-60$} & \multicolumn{2}{|c|}{$42-70$} & \multicolumn{2}{|c|}{$43-65$} & & \\
\hline & No. & $\%$ & No. & $\%$ & No. & $\%$ & & \\
\hline \multicolumn{9}{|l|}{ Gender } \\
\hline Male & 30 & 50.0 & 29 & 48.3 & 42 & 52.5 & \multirow{2}{*}{0.25} & \multirow{2}{*}{0.88} \\
\hline Female & 30 & 50.0 & 31 & 51.7 & 38 & 47.5 & & \\
\hline \multicolumn{9}{|l|}{ Smoking } \\
\hline Yes & 0 & 0.0 & 17 & 28.3 & 38 & 47.5 & \multirow{3}{*}{43.75} & \multirow{3}{*}{$<0.001$} \\
\hline No & 60 & 100.0 & 41 & 68.3 & 42 & 52.5 & & \\
\hline Ex & 0 & 0.0 & 2 & 3.3 & 0 & 0.0 & & \\
\hline \multicolumn{9}{|c|}{ Family history } \\
\hline Yes & 0 & 0.0 & 9 & 15.0 & 22 & 27.5 & \multirow{2}{*}{19.81} & \multirow{2}{*}{$<0.001$} \\
\hline No & 60 & 100.0 & 51 & 85.0 & 58 & 72.5 & & \\
\hline
\end{tabular}

$X=$ mean, $S D=$ standard deviation, $X^{2}=$ chi-square, $P$ probability of error. No $=$ number, $\%=$ percentage ${ }^{*} F=$ one-way ANOVA test

\section{MiR-196a2 gene polymorphism and the risk for HCC}

To evaluate the risk of HCC according to the miR-196a2 genotype using the TT genotype as the reference genotype. Table 4 showed that the TC genotype was associated with a 2.77-fold increased risk of HCC when compared with the TT genotype $(\mathrm{OR}=2.77,95 \% \mathrm{CI}=$ 1.27-6.04). Moreover, the CC genotype was also associated with a 4.94-fold increased risk of HCC compared with the TT genotype $(\mathrm{OR}=4.94,95 \% \mathrm{CI}=1.74-14.07)$. Furthermore, the $\mathrm{TC}+\mathrm{CC}$ genotypes were associated with a 3.24-fold increased risk of HCC when compared with the TT genotype $(\mathrm{OR}=3.24$ and $95 \% \mathrm{CI}=1.55-$ 6.78). Comparing $C$ allele versus $T$ allele distributions in the studied groups, $\mathrm{C}$ allele was significantly associated with an increased risk of HCC with 2.30-fold (OR $=2.30$, 95\% CI = 1.40-3.76) (Table 4).

Additionally, Table 5 showed that there was no statistically significant difference between $\mathrm{HCC}$ and cirrhotic groups as regarding genotypes and alleles $P=0.13,0.09$ respectively. The $\mathrm{TC}+\mathrm{CC}$ genotypes were significantly associated with 2.15-fold increased risk of HCC when compared with the $\mathrm{TT}$ genotype $(\mathrm{OR}=2.15,95 \% \mathrm{CI}=$ $1.01-4.54$.

\section{Relation between the different genotypes and clinico- pathological data among HCC patients}

There was no statistically significant difference between the different genotypes as regards clinical findings (spleen, liver, ascites, child classification, and encephalopathy) (Table 6). Also, there was no statistically significant difference between the different genotypes as regard laboratory investigation (ALT, AST, albumin, total and direct bilirubin, PT Conc\%, and INR and AFP) (Table 7).

\section{Relation between the different genotypes and the aggressiveness of HCC (size and number of focal lesions and AFP level) among HCC patients}

There was no statistically significant difference between the different genotypes regarding either the level of AFP ( $P$ value, 0.76$)$ or the size and number of the focal lesions ( $P$ value, 0.99 ) (Table 8 ). However, $66.7 \%$ of patients with the $\mathrm{CC}$ genotype had a high level of AFP. Moreover, $61.9 \%$ of patients with the CC genotype had multiple focal lesions.

\section{Discussion}

$\mathrm{HCC}$ is the sixth most common cancer worldwide; also it is the third most common cause of mortality and poorsurvival due to the recurrence of HCC and metastasis [7].

The incidence of liver cancer is one of the highest cancers in Egypt, also it is the fifth most common cancer in both genders and the prognosis for patients with $\mathrm{HCC}$ is generally poor [8]. So, early diagnosis of HCC is mandatory for the development of specific curative therapies.

MiRNAs are small, non-coding RNAs which involved in many biological functions, they are critical posttranscriptional regulators in gene expression, modulating cell metabolism, and cell survival [9]. MiRNAs variation may affect its structure and expression. Also, deregulated miRNA and its associated post-transcriptional gene silencing or gene expression suggested being an important part of the pathogenesis of HCC [10].

MiR196 family consists of miR-196-a1, miR196-a2, and miR-196b. Two mature miRNAs, miR-196a-5p, and miR-196a-3p are generated from hsa-mir-196a-2 with the studied polymorphism, rs11614913, residing in the 3' arm. Thus, the potential targets of miR-196a could be influenced by its altered expression patterns [11].

The role of miR-196 in different cancer types is mostly unknown. Although many studies not only suggest the oncogenic function of miR-196, but also it is suggested that miR-196 may play a tumor-suppressive action. If the miR-196 has a dominant action on the inhibition of oncogenic molecules, it will play a tumor suppressor function. However, if the miR-196 mainly targets tumor suppressors, it will play an oncogenic effect [12].

Many studies suggest that miR-196a could play an important role in pathogenesis and malignant behavior of HCC by targeting many genes, such as HOX gene, HMGA2, and annexin A1 [13]. HOX proteins disorders were suggested to play an important role in malignant transformation and metastasis of HCC. ANXA1 involved in many biological processes by acting as a mediator of 
Table $\mathbf{2}$ Lab investigations of the studied groups

\begin{tabular}{|c|c|c|c|c|c|c|c|c|c|}
\hline & \multicolumn{2}{|c|}{$\begin{array}{l}\text { Control } \\
N=60\end{array}$} & \multicolumn{2}{|c|}{$\begin{array}{l}\text { Cirrhosis } \\
N=60\end{array}$} & \multicolumn{2}{|c|}{$\begin{array}{l}\mathrm{HCC} \\
N=80\end{array}$} & Kruskal-Wallis & $P$ value & Post hoc \\
\hline \multicolumn{10}{|l|}{$\mathrm{AST}(\mathrm{U} / \mathrm{L})$} \\
\hline Min-max & \multicolumn{2}{|c|}{$10.0-29.00$} & \multicolumn{2}{|c|}{$12.0-226.00$} & \multicolumn{2}{|c|}{$21.0-540.0$} & & & $\mathrm{P} 1=<0.001$ \\
\hline$X \pm S D$ & \multicolumn{2}{|c|}{$17.30 \pm 4.50$} & \multicolumn{2}{|c|}{$60.56 \pm 43.95$} & \multicolumn{2}{|c|}{$124.26 \pm 204.04$} & 85.26 & $<0.001$ & $P 2=0.02$ \\
\hline Median & \multicolumn{2}{|c|}{17.00} & \multicolumn{2}{|c|}{45.50} & \multicolumn{2}{|c|}{68.50} & & & $\mathrm{P} 3=<0.001$ \\
\hline \multicolumn{10}{|l|}{$\operatorname{ALT}(U / L)$} \\
\hline Min-max & \multicolumn{2}{|c|}{$10.00-27.00$} & \multicolumn{2}{|c|}{$11.0-121.00$} & \multicolumn{2}{|c|}{$11.0-379.0$} & & & $\mathrm{P} 1=<0.001$ \\
\hline$X \pm S D$ & \multicolumn{2}{|c|}{$18.01 \pm 4.81$} & \multicolumn{2}{|c|}{$75.30 \pm 18.73$} & \multicolumn{2}{|c|}{$79.32 \pm 71.51$} & 86.56 & $<0.001$ & $P 2=<0.63$ \\
\hline Median & \multicolumn{2}{|c|}{17.00} & \multicolumn{2}{|c|}{54.00} & \multicolumn{2}{|c|}{55.00} & & & $\mathrm{P} 3=<0.001$ \\
\hline \multicolumn{10}{|c|}{ Albumin (g/dL) } \\
\hline Min-max & 3.70 & & $1.0-4$ & & $2.0-4$ & & & & $\mathrm{P} 1=<0.001$ \\
\hline$X \pm S D$ & 4.42 & & 1.74 & & 2.62 & & 114.31 & $<0.001$ & $P 2=0.32$ \\
\hline Median & 4.40 & & 3.00 & & 3.00 & & & & $\mathrm{P} 3=<0.001$ \\
\hline Total bilirubil & $y / d l)$ & & & & & & & & \\
\hline Min-max & $.20-$ & & 1. 2-1 & & $1.0-2$ & & & & $\mathrm{P} 1=<0.001$ \\
\hline$X \pm S D$ & 0.267 & & $3.20=$ & & 3.45 & & 121.93 & $<0.001$ & $P 2=0.31$ \\
\hline Median & .54 & & 1.20 & & 3.0 & & & & $\mathrm{P} 3=<0.001$ \\
\hline Direct bilirub & $\mathrm{g} / \mathrm{dl})$ & & & & & & & & \\
\hline Min-max & $.06-$ & & 1.00 & & $1.00-$ & & & & $\mathrm{P} 1=<0.001$ \\
\hline$X \pm S D$ & 0.038 & & $3.22=$ & & 3.33 & & 51.30 & $<0.001$ & $P 2=0.30$ \\
\hline Median & .105 & & 1.00 & & 1.50 & & & & $\mathrm{P} 3=<0.001$ \\
\hline Alpha fetopr & $(\mathrm{ng} / \mathrm{n}$ & & & & & & & & \\
\hline Min-max & - & & $1-100$ & & $6-20$ & & & & \\
\hline$X \pm S D$ & & & 13.85 & & 3770 & 1.51 & $9.78^{*}$ & $<0.001$ & ------ \\
\hline Median & & & 4.00 & & 526. & & & & \\
\hline Prothrombin & & & & & & & & & \\
\hline Min-max & $83-1$ & & $40-9$ & & $19-1$ & & & & $\mathrm{P} 1=<0.001$ \\
\hline$X \pm S D$ & 93.67 & & 56.63 & & 58.37 & & 112.96 & $<0.001$ & $P 2=0.87$ \\
\hline Median & 92.50 & & 50.60 & & 57.40 & & & & $\mathrm{P} 3=<0.001$ \\
\hline PT.INR & & & & & & & & & \\
\hline Min-max & $1.00-$ & & 1.02 & & $.95-3$ & & & & $\mathrm{P} 1=<0.001$ \\
\hline$X \pm S D$ & 1.03 & & 1.42 & & 1.48 & & 113.35 & $<0.001$ & $P 2=0.65$ \\
\hline Median & $1.02 \mathrm{C}$ & & 1.43 & & 1.38 & & & & $\mathrm{P} 3=<0.001$ \\
\hline & No & $\%$ & No & $\%$ & No & $\%$ & & & \\
\hline HCV Ab & & & & & & & & & \\
\hline Negative & 60 & 100.0 & 1 & 1.7 & 7 & 8.8 & 16715 & $<0001$ & \\
\hline Positive & 0 & 0.0 & 59 & 98.3 & 73 & 91.2 & 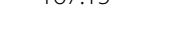 & 0.001 & \\
\hline HBV sAg & & & & & & & & & \\
\hline Negative & 60 & 100.0 & 60 & 100.0 & 78 & 97.5 & & 03 & \\
\hline Positive & 0 & 0.0 & 0 & 0.0 & 2 & 2.5 & 1.90 & הכ. & \\
\hline
\end{tabular}

*Mann-Whitney test

**Fisher's exact test

- P1 = comparison between cirrhosis and control

- P2 = comparison between cirrhosis and HCC

- $\mathrm{P} 3$ = comparison between control and HCC 

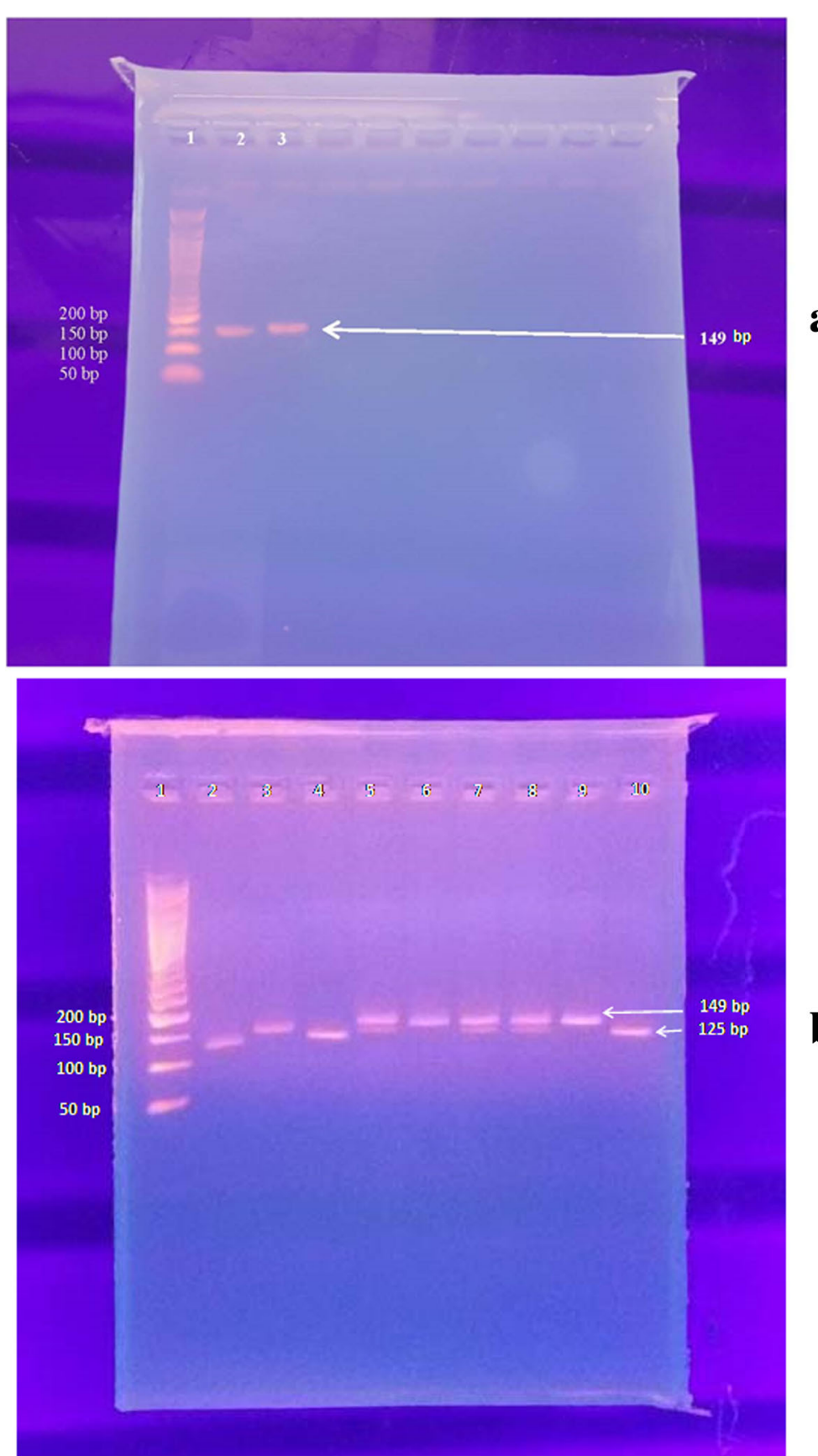

Fig. 1 a Agarose gel electrophoresis for miR-196a2 gene amplification bands correspond to ladder band size (149 bp). b Agarose gel electrophoresis showing PCR-RFLP analysis of miR-196a2 gene after addition restriction enzyme (Mspl). Lanes (ladder): lanes 3, 6, and 9 ( $(T)$ band (149); lanes 5, 7, and 8 (TC) band (149,125, and 24 bp); and lanes 2, 4, and 10 (CC) band (125 and 24 bp)

apoptosis and inhibitor of cell differentiation. So, ANXA1 may participate in the pathogenesis of HCC [14].

SNPs in the miR-196a2 (rs11614913) affect the development of cancer susceptibility due to their targeting on several vital genes [15]. Therefore, the present study was designed to evaluate the role of miR-196a2 rs11614913 polymorphism in the development of HCC in the Egyptian population.
The present study shows that the HCV-positive patients accounted for 73 (91.2\%) and HBs Ag about 2 (2.5\%) of HCC patient group. Dessouky et al. reported that more than $75 \%$ were positive for $\mathrm{HCV}$-antibody among Egyptian patients with HCC [16].

Considering miR-196a2 rs11614913 polymorphism, the results of the present study show that, genotype distribution among the studied groups showed a 
Table 3 Distribution of the genotypes and allele frequencies in three studied groups

\begin{tabular}{|c|c|c|c|c|c|c|c|c|}
\hline & \multicolumn{2}{|c|}{$\begin{array}{l}\text { Control } \\
N=60\end{array}$} & \multicolumn{2}{|c|}{$\begin{array}{l}\text { Cirrhosis } \\
N=60\end{array}$} & \multicolumn{2}{|c|}{$\begin{array}{l}\mathrm{HCC} \\
N=80 \\
\end{array}$} & \multirow[t]{2}{*}{$x^{2}$} & \multirow[t]{2}{*}{$P$ value } \\
\hline & No. & $\%$ & No. & & & $\%$ & & \\
\hline \multicolumn{9}{|c|}{ Polymorphism } \\
\hline$\pi$ & 28 & 46.7 & 22 & 36.7 & 17 & 21.3 & \multirow{3}{*}{11.7} & \multirow{3}{*}{0.02} \\
\hline TC & 25 & 41.6 & 25 & 41.6 & 42 & 52.4 & & \\
\hline $\mathrm{CC}$ & 7 & 11.7 & 13 & 21.7 & 21 & 26.3 & & \\
\hline \multicolumn{9}{|c|}{ Polymorphism } \\
\hline$\pi$ & 28 & 46.7 & 22 & 36.7 & 17 & 21.3 & \multirow{2}{*}{10.33} & \multirow{2}{*}{0.005} \\
\hline$(T C+C C)$ & 32 & 53.3 & 38 & 63.3 & 63 & 78.7 & & \\
\hline \multicolumn{9}{|l|}{ Allele } \\
\hline $\mathrm{T}$ & 81 & 67.5 & 69 & 57.5 & 76 & 47.5 & \multirow{2}{*}{11.23} & \multirow{2}{*}{0.003} \\
\hline$C$ & 39 & 32.5 & 51 & 42.5 & 84 & 52.5 & & \\
\hline
\end{tabular}

statistically significant difference between HCC patients and each of the other groups. HCC patients had a higher incidence of $\mathrm{CC}$ and $\mathrm{TC}$ genotypes when compared to cirrhotic patients and healthy controls $(P=0.02,0.005)$, respectively. Allele frequencies showed a statistically higher incidence of $\mathrm{C}$ allele in HCC patients compared to cirrhotic patients and healthy controls $(P=0.003)$.

These results are similar to the results obtained by $\mathrm{Li}$ et al. and Yan et al. who found that there was a significant difference in the distribution of miR-196a2 genotypes and alleles between HCC cases and the two other groups $[17,18]$.

In contrast with the present study, Chu et al. stated that the miR-196a2 genotype distribution among HCC patients was not significantly different from that among the two other groups [19].

Table 4 Comparison of polymorphism between Control and HCC groups

\begin{tabular}{|c|c|c|c|}
\hline $\begin{array}{l}\text { Control } \\
N=60\end{array}$ & $\begin{array}{l}\mathrm{HCC} \\
\mathrm{N}=80\end{array}$ & $x^{2}$ & $P$ value \\
\hline Jo. \% & No. \% & & \\
\hline
\end{tabular}

\begin{tabular}{|c|c|c|c|c|c|c|c|}
\hline \multicolumn{8}{|c|}{ Polymorphism } \\
\hline$\pi$ & 28 & 46.7 & 17 & 21.3 & \multirow{3}{*}{11.38} & \multirow{3}{*}{0.003} & $\Pi$ is a reference \\
\hline TC & 25 & 41.6 & 42 & 52.4 & & & $C C=4.94[1.74-14.07]$ \\
\hline $\mathrm{CC}$ & 7 & 11.7 & 21 & 26.3 & & & $\mathrm{TC}=2.77[1.27-6.04]$ \\
\hline \multicolumn{8}{|c|}{ Polymorphism } \\
\hline$\pi$ & 28 & 46.7 & 17 & 21.3 & 10.15 & \multirow{2}{*}{0.001} & \multirow[t]{2}{*}{3.24 [1.55-6.78] } \\
\hline$(\mathrm{TC}+\mathrm{CC})$ & 32 & 53.3 & 63 & 78.7 & & & \\
\hline \multicolumn{8}{|l|}{ Allele } \\
\hline $\mathrm{T}$ & 81 & 67.5 & 76 & 47.5 & 11.14 & \multirow{2}{*}{0.0008} & \multirow[t]{2}{*}{$2.30[1.40-3.76]$} \\
\hline C & 39 & 32.5 & 84 & 52.5 & & & \\
\hline
\end{tabular}

Table 5 Comparison of polymorphism between Cirrhosis and HCC groups

\begin{tabular}{|c|c|c|c|c|c|c|c|}
\hline & \multicolumn{2}{|c|}{$\begin{array}{l}\text { Control } \\
N=60\end{array}$} & \multicolumn{2}{|c|}{$\begin{array}{l}\mathrm{HCC} \\
N=80\end{array}$} & \multirow[t]{2}{*}{$x^{2}$} & \multirow[t]{2}{*}{$P$ value } & \multirow[t]{2}{*}{$\mathrm{OR}(95 \% \mathrm{Cl})$} \\
\hline & No. & $\%$ & No. & $\%$ & & & \\
\hline \multicolumn{8}{|c|}{ Polymorphism } \\
\hline$\pi$ & 22 & 36.7 & 17 & 21.3 & \multirow{3}{*}{4.06} & \multirow{3}{*}{0.13} & $\Pi$ is a reference \\
\hline TC & 25 & 41.6 & 42 & 52.4 & & & $C C=2.09[0.82-5.34]$ \\
\hline CC & 13 & 21.7 & 21 & 26.3 & & & $\mathrm{TC}=2.17[0.97-4.86]$ \\
\hline \multicolumn{8}{|c|}{ Polymorphism } \\
\hline$\pi$ & 22 & 36.7 & 17 & 21.3 & \multirow{2}{*}{4.05} & \multirow{2}{*}{0.04} & \multirow[t]{2}{*}{$2.15[1.01-4.54]$} \\
\hline$(\mathrm{TC}+\mathrm{CC})$ & 38 & 63.3 & 63 & 78.7 & & & \\
\hline \multicolumn{8}{|l|}{ Allele: } \\
\hline $\mathrm{T}$ & 69 & 57.5 & 76 & 47.5 & \multirow{2}{*}{2.75} & \multirow{2}{*}{0.09} & \multirow[t]{2}{*}{$1.50[0.93-2.41]$} \\
\hline$C$ & 51 & 42.5 & 84 & 52.5 & & & \\
\hline
\end{tabular}

Also in a meta-analysis done by Liu et al. [20], it has been found that the miR-196a2 genotypes were associated with a decreased susceptibility of HCC frequency.

On the other hand, Tian and his colleagues reported that the distribution of the miR-196a2 (rs11614913) polymorphism did not affect HCC susceptibility [5].

In the present study, the comparison of the polymorphism between the control and the HCC groups confirmed that both TC genotype and CC genotype were associated with a significantly increased risk of HCC when compared with the TT genotype.

Moreover, when comparing $(\mathrm{C})$ allele versus $(\mathrm{T})$ allele distributions in the studied groups, $\mathrm{C}$ allele was found to be associated with a significantly increased risk of HCC with 2.30 -fold ( $\mathrm{OR}=2.30,95 \% \mathrm{CI}=1.40-3.76)$.

Our results are comparable to the results obtained by Zhao et al. [21], who found that both CC genotype and $\mathrm{C}$ allele is at increased risk for $\mathrm{HCC}$ " $\mathrm{CC}$ vs TT (OR = $1.302,95 \% \mathrm{CI}=1.019-1.663)$ and $\mathrm{C}$ vs. $\mathrm{T}(\mathrm{OR}=1.130$, 95\% CI $=1.004-1.272)$ ".

Also, Yan et al. [18] reported that individuals carrying the TC and CC genotypes of miR-196a2 were found to be associated with an elevated risk of HCC compared to the TT genotype, with an adjusted odds ratio of 1.50 (1.03-2.17) and 2.86(1.60-5.16), respectively.

In contrast to the present study, Chu et al. [19] suggested that the interaction between studied gene polymorphisms and cancer risk factors was not statistically significant.

The present study shows that the TC + CC genotypes were significantly associated with 3.24-fold increased risk of HCC when compared with the TT genotype $(\mathrm{OR}=$ $3.24,95 \% \mathrm{CI}=1.55-6.78)$.

$\mathrm{Li}$ et al. documented that the $\mathrm{TC}+\mathrm{CC}$ genotypes of rs11614913 polymorphism were significantly associated with an increased risk of HCC (TT vs. CT + CC: OR = $2.52,95 \% \mathrm{CI}=1.18-4.19 ; P<0.05)[22]$. 
Table 6 Relation between genotypes and socio-demographic data among HCC patients

\begin{tabular}{|c|c|c|c|c|c|c|c|c|}
\hline \multirow[t]{2}{*}{ Studied variable } & \multicolumn{6}{|c|}{ Genotype } & \multirow[t]{2}{*}{ Chi-square test } & \multirow[t]{2}{*}{$P$ value } \\
\hline & \multicolumn{2}{|c|}{$\begin{array}{l}C C \\
N=21\end{array}$} & \multicolumn{2}{|c|}{$\begin{array}{l}\mathrm{TC} \\
N=42\end{array}$} & \multicolumn{2}{|c|}{$\begin{array}{l}\Pi \\
N=17\end{array}$} & & \\
\hline \multirow[t]{2}{*}{ Age (years) $X \pm S D$} & \multicolumn{2}{|c|}{$52.50 \pm 4.628$} & \multicolumn{2}{|c|}{$54.48 \pm 4.77$} & \multicolumn{2}{|c|}{$56.06 \pm 6.329$} & \multirow[t]{2}{*}{$2.96^{*}$} & \multirow[t]{2}{*}{0.06} \\
\hline & No. & $(\%)$ & No. & (\%) & No. & $(\%)$ & & \\
\hline \multicolumn{9}{|l|}{ Gender } \\
\hline Male & 10 & (47.6) & 20 & $(47.6)$ & 12 & (70.6) & \multirow{2}{*}{0.49} & \multirow{2}{*}{0.78} \\
\hline Female & 11 & (52.4) & 22 & (52.4) & 5 & (29.4) & & \\
\hline \multicolumn{9}{|l|}{ Smoking } \\
\hline Yes & 12 & (57. 1) & 16 & (38. 1) & 10 & (58.8) & \multirow{2}{*}{3.15} & \multirow{2}{*}{0.20} \\
\hline No & 9 & (42.9) & 26 & (61.9) & 7 & $(41.2)$ & & \\
\hline \multicolumn{9}{|l|}{ Family history } \\
\hline Yes & 5 & (23.8) & 12 & (28.6) & 5 & (29.4) & \multirow{2}{*}{0.20} & \multirow{2}{*}{0.90} \\
\hline No & 16 & $(76.2)$ & 30 & (71.4) & 12 & (70.6) & & \\
\hline \multicolumn{9}{|l|}{ Spleen } \\
\hline Average & 5 & (23.8) & 5 & (11.9) & 1 & (5.9) & \multirow{2}{*}{$2.50^{* *}$} & \multirow{2}{*}{0.25} \\
\hline Splenomegaly & 16 & $(76.2)$ & 37 & (88.1) & 16 & $(94.1)$ & & \\
\hline \multicolumn{9}{|l|}{ Liver } \\
\hline Hepatomegaly & 6 & (28.6) & 7 & (16.7) & 5 & (29.4) & \multirow{3}{*}{3.01} & \multirow{3}{*}{0.55} \\
\hline Cirrhotic & 14 & $(66.7)$ & 34 & (81.0) & 12 & (70.6) & & \\
\hline Shrunken & 1 & (4.8) & 1 & (2.4) & 0 & $(0.0)$ & & \\
\hline \multicolumn{9}{|l|}{ Ascites } \\
\hline Present & 16 & $(76.2)$ & 38 & (90.5) & 13 & (76.5) & \multirow{2}{*}{3.20} & 020 \\
\hline No & 5 & (23.8) & 4 & (9.5) & 4 & (23.5) & & 0.20 \\
\hline Encephalopathy & & & & & & & & \\
\hline Present & 12 & (57.1) & 28 & $(66.7)$ & 10 & (58.8) & 066 & \\
\hline Absent & 9 & (42.9) & 14 & (33.3) & 7 & $(41.2 \%)$ & 0.00 & 0.71 \\
\hline Child score & & & & & & & & \\
\hline A & 7 & (33.3) & 13 & (31.0) & 4 & (23.5) & & \\
\hline B & 6 & (28.6) & 17 & $(40.5)$ & 6 & (35.3) & $1.61^{* *}$ & 0.80 \\
\hline C & 8 & (38.1) & 12 & (28.6) & 7 & $(41.2)$ & & \\
\hline
\end{tabular}

*ANOVA test

**Fisher's exact test

Also, Chen et al. [12] stated that the rs11614913 polymorphism of miR-196a-2 carry a significant increased risk for $\mathrm{HCC}$ development $(\mathrm{C}$ vs $\mathrm{T}: \mathrm{OR}=1.14,95 \% \mathrm{CI}=$ $1.06-1.23, P=0.001 ; \mathrm{CC}$ vs TT: $\mathrm{OR}=1.31,95 \% \mathrm{CI}=$ $1.12-1.53, P=0.001 ; \mathrm{TC}+\mathrm{CC}$ vs TT: $\mathrm{OR}=1.16,95 \%$ $\mathrm{CI}=1.03-1.31, P=0.018 ; \mathrm{CC}$ vs TT: $\mathrm{OR}=1.14,95 \% \mathrm{CI}=$ $1.00-1.30, P=0.043$ ).

In the contrary, a meta-analysis done by Peng et al. [23] stated that there was no evidence of significant association between miR-196a2 rs11614913 polymorphism and HCC risk when all eligible studies were pooled into the meta-analysis $(\mathrm{CC}$ vs $\mathrm{TT}$ : $\mathrm{OR}=1.287,95 \% \mathrm{CI}=$ $0.931-1.607, P=0.226$; $\mathrm{TC}$ vs TT: $\mathrm{OR}=1.055,95 \% \mathrm{CI}=$ $0.958-1.161, P=0.278 ; \mathrm{TC}+\mathrm{CC}$ vs TT: $\mathrm{OR}=1.134$, $95 \% \mathrm{CI}=0.974-1.320, P=0.105$.

Additionally, the results obtained by Kim and his colleagues reported that the miR-196a-2 rs12304647 CC genotype had a protective effect against the development of $\mathrm{HCC}$ in patients with chronic hepatitis B infection and cirrhosis [24].

In the present study, there is no statistically significant difference between HCC and cirrhotic groups as regarding genotypes and alleles $P=0.13,0.09$, respectively.

Study of the correlation between miR-196a 2 genotypes and personal history and clinical data, including spleen, liver, ascites, child classification, encephalopathy, and tumor size, shows that there was no statistically significant difference data among HCC patients as regards personal history and clinical data.

Chu et al. [19] suggested that a significant association between miRNA499 SNPs and HCC is present. However, gene-environmental interactions of miRNA499 polymorphisms, smoking, and alcohol consumption might alter the HCC susceptibility. 
Table 7 Relation between genotypes and clinicopathological data among HCC patients

\begin{tabular}{|c|c|c|c|c|c|}
\hline \multirow[t]{2}{*}{ Studied variable } & \multicolumn{3}{|l|}{ Genotype } & \multirow[t]{2}{*}{ Kruskal-Wallis test } & \multirow[t]{2}{*}{$P$ value } \\
\hline & $\begin{array}{l}C C \\
N=21\end{array}$ & $\begin{array}{l}\text { TC } \\
N=42\end{array}$ & $\begin{array}{l}\Pi \\
N=17\end{array}$ & & \\
\hline \multicolumn{6}{|l|}{ AST (U/L) } \\
\hline Min-max & $12.0-302.0$ & $21.0-540.0$ & $14.00-258.00$ & & \\
\hline$X \pm S D$ & $83.96 \pm 70.88$ & $158.04 \pm 269.99$ & $90.56 \pm 78.90$ & 0.38 & 0.82 \\
\hline Median & 67.50 & 93.00 & 66.00 & & \\
\hline \multicolumn{6}{|l|}{$\mathrm{ALT}(\mathrm{U} / \mathrm{L})$} \\
\hline Min-max & $11.0-292.00$ & $12.0-379.0$ & $11.0-205.0$ & & \\
\hline$X \pm S D$ & $80.14 \pm 61.68$ & $83.57 \pm 83.45$ & $67.82 \pm 49.62$ & 1.10 & 0.57 \\
\hline Median & 64.000000 & 59.00 & 53.0 & & \\
\hline \multicolumn{6}{|l|}{ ALB (g/dL) } \\
\hline Min-max & $2.0-4.0$ & $2.0-4.0$ & $2.0-4.0$ & & \\
\hline$X \pm S D$ & $2.73 \pm .70$ & $2.54 \pm .58$ & $2.61 \pm .67$ & 1.25 & 0.53 \\
\hline Median & 3.0 & 3.00 & 2.0 & & \\
\hline \multicolumn{6}{|l|}{ BT (mg/dL) } \\
\hline Min-max & $1.0-16.0$ & $1.0-20.0$ & $1.0-9.0$ & & \\
\hline$X \pm S D$ & $4.03 \pm 3.96$ & $3.66 \pm 3.54$ & $3.36 \pm 2.43$ & 0.05 & 0.97 \\
\hline Median & 2.0 & 3.00 & 3.00 & & \\
\hline \multicolumn{6}{|l|}{$\mathrm{BD}(\mathrm{mg} / \mathrm{dL})$} \\
\hline Min-max & $1.0-16.0$ & $1.0-15.00$ & $1.0-8.0$ & & \\
\hline$X \pm S D$ & $3.58 \pm 4.46$ & $2.55 \pm 2.92$ & $3.03 \pm 2.56$ & 0.94 & 0.62 \\
\hline Median & 1.00 & 1.0 & 2.0 & & \\
\hline \multicolumn{6}{|l|}{ AFP (ng/mL) } \\
\hline Min-max & $12-5200$ & $11-20,949$ & $6-19,007$ & & \\
\hline$X \pm S D$ & $1586.48 \pm 1513.68$ & $1801.07 \pm 4254.21$ & $2052.71 \pm 4561.92$ & 3.35 & 0.18 \\
\hline Median & 615.00 & 420.00 & 680.00 & & \\
\hline \multicolumn{6}{|l|}{ Focal lesion } \\
\hline Min-max & $1.50-9.00$ & $1.50-8.00$ & $2.00-11.00$ & & \\
\hline$X \pm S D$ & $4.81 \pm 2.10$ & $3.99 \pm 1.72$ & $4.75 \pm 2.07$ & 1.5 & 0.22 \\
\hline Median & 5.00 & 4.0 & 4.50 & & \\
\hline \multicolumn{6}{|l|}{ PT. conc } \\
\hline Min-max & $19-96$ & $20-102$ & $29-89$ & & \\
\hline$X \pm S D$ & $56.26 \pm 18.66$ & $59.40 \pm 16.54$ & $58.43 \pm 16.53$ & 0.73 & 0.69 \\
\hline Median & 55.00 & 63.00 & 57.00 & & \\
\hline \multicolumn{6}{|l|}{ PT.INR } \\
\hline Min-max & $1.03-2.71$ & $.95-3.59$ & $1.08-2.40$ & & \\
\hline$X \pm S D$ & $1.54 \pm .45$ & $1.45 \pm .45$ & $1.47 \pm .37$ & 0.61 & 0.73 \\
\hline Median & 1.4150 & 1.3300 & 1.45 & & \\
\hline
\end{tabular}

Studying the correlation between miR-196a2 rs11614913 genotypes and laboratory characteristics, there was no statistically significant difference between the different genotypes among the $\mathrm{HCC}$ cases regarding lab investigations (ALT, AST, albumin, total and direct bilirubin, INR, and AFP).

In our analysis of the association between this polymorphism and the HCC aggressiveness as regards the AFP level and size and number of the focal lesions, we noticed that there was no statistically significant difference between the different genotypes regarding either the level of AFP ( $P$ value, 0.76 ) or the size and number of the focal lesions ( $P$ value, 0.99 ). However, $66.7 \%$ of patients with the $\mathrm{CC}$ genotype had a high level of AFP. Moreover, $61.9 \%$ of patients with the CC genotype had multiple focal lesions.

$\mathrm{Li}$ and his co-workers reported that, in a subsequent analysis of the association between microRNA$196 \mathrm{a} 2$ and clinic-pathological characteristics, there was an association between rs11614913 genotype and 
Table 8 Relation between the different genotypes and the aggressiveness of HCC (size and number of focal lesions and AFP level) among HCC patients

\begin{tabular}{|c|c|c|c|c|c|c|c|c|}
\hline \multirow[t]{3}{*}{ Studied variable } & \multicolumn{6}{|c|}{ Genotype } & \multirow[t]{3}{*}{ Chi-square test } & \multirow[t]{3}{*}{$P$ value } \\
\hline & \multicolumn{2}{|c|}{$\begin{array}{l}C C \\
N=21\end{array}$} & \multicolumn{2}{|c|}{$\begin{array}{l}\text { TC } \\
N=42\end{array}$} & \multicolumn{2}{|c|}{$\begin{array}{l}\Pi T \\
N=17\end{array}$} & & \\
\hline & No. & $(\%)$ & No. & $\overline{(\%)}$ & No. & $(\%)$ & & \\
\hline \multicolumn{9}{|l|}{ AFP } \\
\hline$<=400$ & 7 & 33.3 & 18 & 42.9 & 7 & 41.2 & \multirow{2}{*}{0.54} & \multirow{2}{*}{0.76} \\
\hline$>400$ & 14 & 66.7 & 24 & 57. 1 & 0 & 58.8 & & \\
\hline \multicolumn{9}{|l|}{ Focal lesion size } \\
\hline$<=3$ & 9 & 42.9 & 18 & 42.9 & 7 & 41.2 & \multirow{2}{*}{0.01} & \multirow{2}{*}{0.99} \\
\hline$>3$ & 12 & 57.1 & 24 & 57.1 & 10 & 58.8 & & \\
\hline \multicolumn{9}{|c|}{ No. of focal lesion: } \\
\hline Multiple & 10 & 47.6 & 26 & 61.9 & 10 & 58.8 & \multirow{2}{*}{1.18} & \multirow{2}{*}{0.55} \\
\hline Single & 11 & 52.4 & 16 & 38.1 & 7 & 41.2 & & \\
\hline
\end{tabular}

tumor size $(P=0.046)$, but not with tumor number [17].

\section{Conclusion}

The findings of this study suggested that miR-196a2 polymorphism is associated with HCC risk in the Egyptian population. More well-designed studies based on larger sample sizes and more ethnic groups are still needed in the future.

\section{Abbreviations \\ AFP: Alpha-fetoprotein; ALT: Alanine aminotransferase; AST: Aspartate aminotransferase; bp: Base pair; CT: Computed tomography; \\ DNA: Deoxyribonucleic acid; EDTA: Ethylenediaminetetraacetic acid; HBV: Hepatitis B virus; HCC: Hepatocellular carcinoma; HCV: Hepatitis C virus; HOX: Homeobox; INR: International normalized ratio; miR: MicroRNA; NASH: Non-alcoholic steatohepatitis; PCR-RFLP: Polymerase chain reaction- restriction fragment length polymorphism; SNP: Single-nucleotide polymorphism}

\section{Acknowledgements}

The authors would like to thank our colleagues in the Department of Laboratory Medicine and the patients in the National Liver Institute who helped in this work.

\section{Authors' contributions}

All authors read and approved the final manuscript. EG had selected the idea and design of the work and had made the final revision of data. GR did the data gathering, analysis, and manuscript preparation. EO and AS did the data gathering and manuscript preparation. EA did the design, data gathering, analysis, and manuscript preparation.

\section{Funding}

This research did not receive any specific grant from funding agencies in the public, commercial, or not-for-profit sectors.

\section{Availability of data and materials}

The datasets generated and/or analyzed during the current study are not publicly available due to confidential and institutional ethical issues but, are available from the corresponding author on reasonable request.

\section{Ethics approval and consent to participate}

The study was conducted in accordance with the ethical principles of the 1975 Declaration of Helsinki, and it was reviewed and approved by the Research Ethics Committee of National Liver Institute, Menoufia University.
Written informed consent was obtained from all the participants after explaining the aim and concerns of the study (ethics committee reference number: not available).

\section{Consent for publication}

Not applicable.

\section{Competing interests}

The authors declare that they have no competing interests.

Received: 25 October 2019 Accepted: 23 January 2020

Published online: 01 April 2020

\section{References}

1. Ren W, Wu S, Wu Y et al (2019) MicroRNA-196a/-196b regulate the progression of hepatocellular carcinoma through modulating the JAKVSTAT pathway via targeting SOCS2. Cell Death Dis 10(5):333

2. Mohammed K Zahra, Taher E Attia, Amira Y Ahmad et al (2018) Serum galectin-3 levels in patients with hepatocellular carcinoma, liver cirrhosis and chronic viral hepatitis. Egypt J Hospital Med 70 (1): 132-139

3. Karabegović I, Maas S, Medina-Gomez C et al (2017) Genetic polymorphism of miR-196a-2 is associated with bone mineral density (BMD). Int J Mol Sci 18(12):2529

4. Zheng L, Zhuang C, Zhao J et al (2017) Functional miR-146a, miR-149, miR$196 a 2$ and miR-499 polymorphisms and the susceptibility to hepatocellular carcinoma: an updated meta-analysis. Clin Res Hepatol Gastroenterol 41(6): 664-676

5. Tian T, Wang M, Zhu W et al (2017) MiR-146a and miR-196a-2 polymorphisms are associated with hepatitis virus-related hepatocellular cancer risk: a meta-analysis. Aging 9(2):381-392

6. Tutar Y (2014) miRNA and Cancer; computational and experimental approaches. Curr Pharm Biotechnol 15(5):429-429

7. Peng C, Ye Y, Wang Z et al (2019) Circulating microRNAs for the diagnosis of hepatocellular carcinoma. Dig Liver Dis 51(5):621-631

8. Azim HA, Omar A, Atef $\mathrm{H}$ et al (2018) Sorafenib plus tegafur-uracil (UFT) versus sorafenib as first line systemic treatment for patients with advanced stage HCC: a phase II trial (ESLC01 study). J Hepatocellular Carcinoma 5:109-119

9. Zhu B, Gong Y, Yan G et al (2018) Down-regulation of IncRNA MEG3 promotes hypoxia-induced human pulmonary artery smooth muscle cell proliferation and migration via repressing PTEN by sponging miR-21. Biochem Biophys Res Commun 495:2125-2132

10. Yin W, Zhao Y, Ji Y-J et al (2015) Serum/plasma microRNAs as biomarkers for HBV-related hepatocellular carcinoma in China. Bio Med Res Int. Article ID: 965185

11. Choupani J, Nariman-Saleh-Fam Z, Saadatian Z et al (2019) Association of mir-196a-2 rs11614913 and mir-149 rs2292832 polymorphisms with risk of cancer: an updated meta-analysis. Front Genet 10:186

12. Chen C, Zhang Y, Zhang L et al (2011) MicroRNA-196: critical roles and clinical applications in development and cancer. J Cell Mol Med 15(1):14-23

13. Rapado-González Ó, López-López R, López-Cedrún J et al (2019) Cell-Free microRNAs as Potential Oral Cancer Biomarkers: From Diagnosis to Therapy. Cells 8(12):1653

14. Wang Z, Cao Y, Jiang C et al (2012) Lack of association of two common polymorphisms rs2910164 and rs11614913 with susceptibility to hepatocellular carcinoma: a meta-analysis. PLoS One 7(6):e40039

15. Liu Z, Li G, Wei S et al (2010) Genetic variants in selected pre-microRNA genes and the risk of squamous cell carcinoma of the head and neck. Cancer 116:4753-4760

16. Dessouky BA, Mousa WA, Abd El-Shafy AF (2018) Role of computed tomography in prediction of tumor necrosis of hepatocellular carcinoma after chemoembolization. Menoufia Med J 31:531-537

17. Li X, Li Z, Song X et al (2010) A variant in microRNA-196a2 is associated with susceptibility to hepatocellular carcinoma in Chinese patients with cirrhosis. Pathology 42(7):669-673

18. Yan P, Xia M, Gao F et al (2015) Predictive role of miR-146a rs2910164 (C>G), miR-149 rs2292832 (T>C), miR-196a2 rs11614913 ( $>C$ ) and miR-499 rs3746444 (T>C) in the development of hepatocellular carcinoma. Int J Clin Exp Pathol 8(11):15177-15183

19. Chu Y-H, Hsieh M-J, Chiou H-L et al (2014) MicroRNA gene polymorphisms and environmental factors increase patient susceptibility to hepatocellular carcinoma. PLoS One 9(2):e89930 
20. Liu Y, He A, Liu B et al (2018) rs11614913 polymorphism in miRNA-196a2 and cancer risk: an updated meta-analysis. OncoTargets Therapy 11:11211139

21. Zhao R, Zhou J, Liu F et al (2016) The association between miR-196a2 rs 11614913 polymorphism and digestive system cancer risk: a meta-analysis of 34 studies. Open J Internal Med 6(04):112-127

22. Li J, Cheng G, Wang S (2016) A single-nucleotide polymorphism of miR$196 a 2 T>C$ rs11614913 is associated with hepatocellular carcinoma in the Chinese population. Genet Test Mol Biomarkers 20(4):213-215

23. Peng Q, Li S, Lao X et al (2014) The association of common functional polymorphisms in mir-146a and mir-196a2 and hepatocellular carcinoma risk: evidence from a meta-analysis. Medicine 93(29):e252

24. Kim HY, Yoon JH, Lee HS et al (2014) MicroRNA-196A-2 polymorphisms and hepatocellular carcinoma in patients with chronic hepatitis B. J Med Virol 86(3):446-453

\section{Publisher's Note}

Springer Nature remains neutral with regard to jurisdictional claims in published maps and institutional affiliations.

\section{Submit your manuscript to a SpringerOpen ${ }^{\circ}$ journal and benefit from:}

- Convenient online submission

- Rigorous peer review

- Open access: articles freely available online

- High visibility within the field

- Retaining the copyright to your article

Submit your next manuscript at $\boldsymbol{\wedge}$ springeropen.com 